\title{
American Pediatric Society John Howland Award 2002: Presentation
}

\author{
NORMAN J. SIEGEL \\ Yale University School of Medicine, New Haven, CT 06520-8064, U.S.A.
}

This morning I have the great pleasure and high honor of introducing to you the recipient of the 2002 Howland Award, Howard A. Pearson. Dr. Pearson was born in the Gorgas Hospital in Panama Canal Zone. At 9 years of age, his family moved to Lynn, MA, where Howard attended public schools and pursued the usual high school activities of a small, sport crazy, New England city (Fig. 1). He distinguished himself by earning the Eagle Scout Award at the age of 15 concomitant with carving his first totem pole, an activity to which he was destined to return much later.

He attended Dartmouth College, where he outfitted himself with skills which are essential for the pursuit of a distinguished career of academic achievement and national leadership (Fig. 2). He graduated from Dartmouth Magna cum Laude and was elected to Phi Beta Kappa. During the summer of 1949, while working as a house boy at a small hotel on Cape Cod, he met and courted Anne Livingston, who was a waitress. Howard and Anne have enjoyed a rich and fruitful life, which includes five children and 14 grandchildren. He attended Dartmouth Medical School for 2 years and then transferred to Harvard School of Medicine, from which he received the M.D. degree.

He served his internship and was a resident in Pediatrics at the U.S. Naval Hospital in Bethesda, MD, under the tutelage and guidance of Dr. Thomas E. Cone, Jr., who was Howard's first pediatric mentor and a very important influence on his career. After completing his residency, he entered a pediatric hematology fellowship program at Boston Children's Hospital, where he studied with Dr. Louis K. Diamond, who stimulated his interests in pediatric hematology and clinical research. After completing his fellowship, Howard returned to the U.S. Naval Hospital in Bethesda as Assistant Chief of Pediatrics and held clinical appointments at Georgetown and Howard Medical Schools.

In 1962, he moved to the newly opened University of Florida School of Medicine in Gainesville. There were many unusual and distinct opportunities in Gainesville. As Howard developed a new Division of Pediatric Hematology/Oncology, he took on a number of difficult challenges, including the study of animal models of human diseases (Fig. 3). He rose rapidly

Received June 17, 2002; accepted July 24, 2002.

Correspondence: Norman J. Siegel, M.D., Yale University School of Medicine, P.O. Box 208064, 333 Cedar Street, New Haven, CT 06520-8064, U.S.A.; e-mail: Norman.siegel@yale.edu

Presented at the 2002 Annual Meeting of the Pediatric Academic Societies, Baltimore, Maryland, U.S.A.

DOI: 10.1203/01.PDR.0000052081.04334.C5

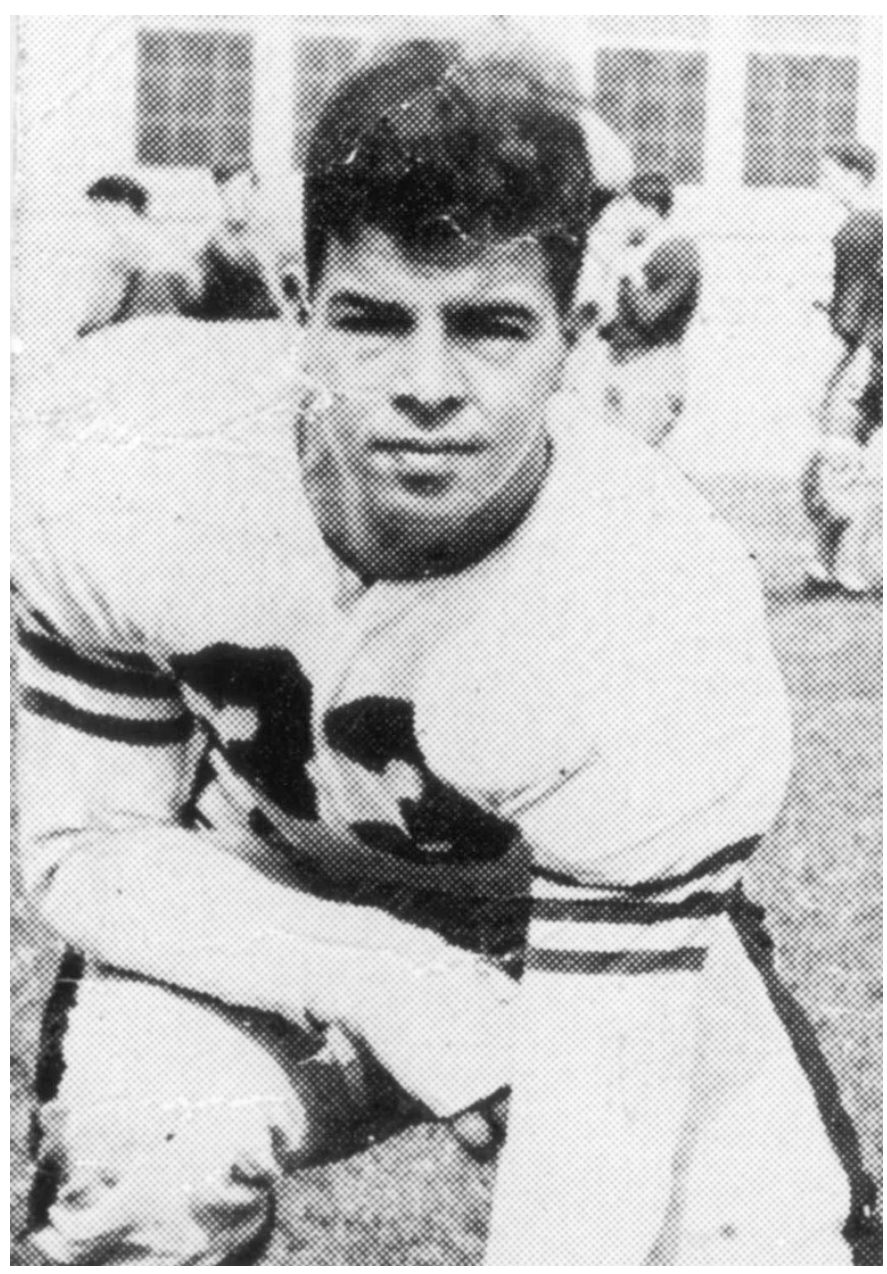

Figure 1. Howard Pearson as a varsity center, Lynn English High School, 1946.

through the ranks from assistant professor to full professor in 6 years while receiving a number of teaching awards from medical students, zoo keepers, and housestaff and publishing prodigiously. In 1968, he was recruited to Yale School of Medicine as professor of pediatrics and chief of the yet-to-bedeveloped Division of Pediatric Hematology/Oncology. Six years later, he was selected to be chairman of the Department of Pediatrics at Yale, a position which he held until 1987. This was a time of tremendous growth in academic pediatrics at Yale, and Howard brought together an outstanding department, created 10 subspecialty divisions as well as one of the first sections of general pediatrics in an academic center. He was a 


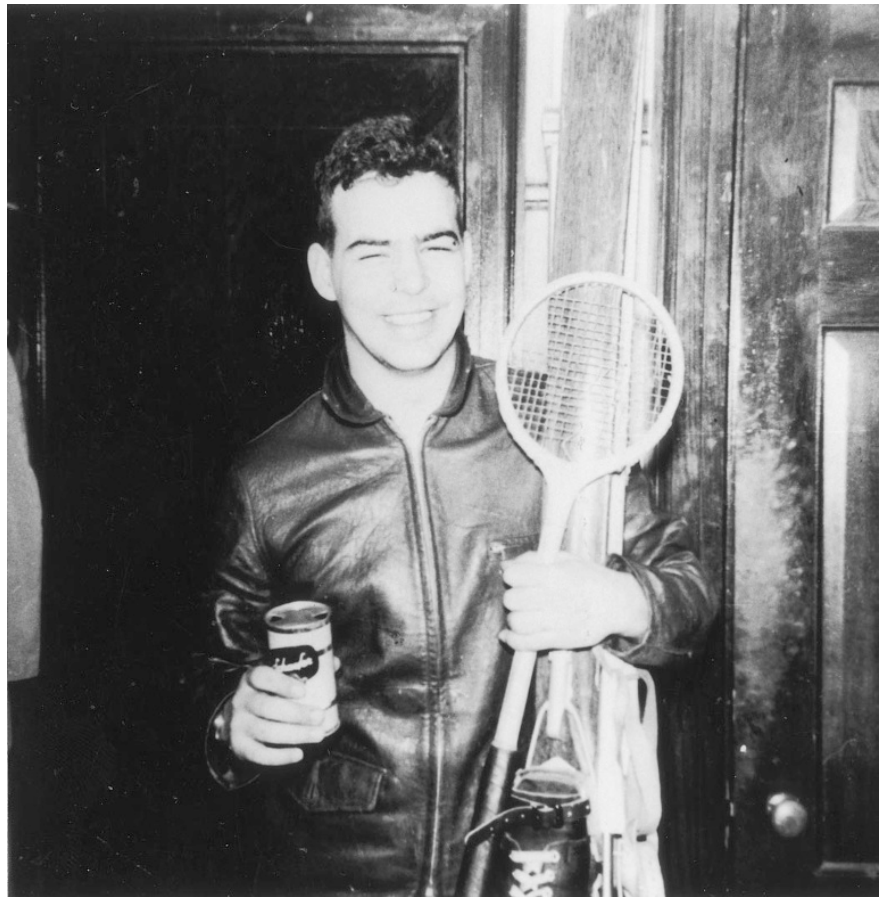

Figure 2. Howard Pearson at Dartmouth College, 1948.

consistent and excellent role model for young faculty. He promoted a departmental research environment that was able to attract young, aggressive investigators, but he never lost sight of student teaching, resident education, and advancing the health of children by supporting the primary care pediatricians in our community. During this 13-year period, 225 pediatric residents completed their education in the department, the majority of them sought careers in academic pediatrics, and many are now faculty members and division chiefs across the country. Howard's leadership at Yale is perhaps best summarized by the inscription on a plaque in the Pearson Conference Room on the Pediatric In-patient unit at Yale New Haven Hospital: "Challenged by his teaching, educated by his wisdom, inspired by his dedication to the highest quality of care for infants, children and adolescents."

Even while he was departmental chairman at Yale, he continued his involvement in clinical research. In 1980, he described a new condition which has been given the eponym Pearson's marrow pancreas syndrome that results from large deletions of mitochondrial DNA. This was especially gratifying to Howard, who has never met a syndrome that he didn't love.

Howard Pearson's impact as an academic pediatric hematologist has had far-reaching effects on the understanding of children and their diseases, some of which he will discuss. Howard's work has also been of critical importance in preventing illness and promoting health, particularly for children with chronic illnesses. While serving on the AAP Committee on Nutrition from 1966 to 1972, he authored the Committee's statement Iron Balance and Requirements in Infancy. This statement advocated the use of iron-fortified infant formula when breast-feeding was not used. On the basis of this recommendation, when the Women, Infants and Children (WIC)

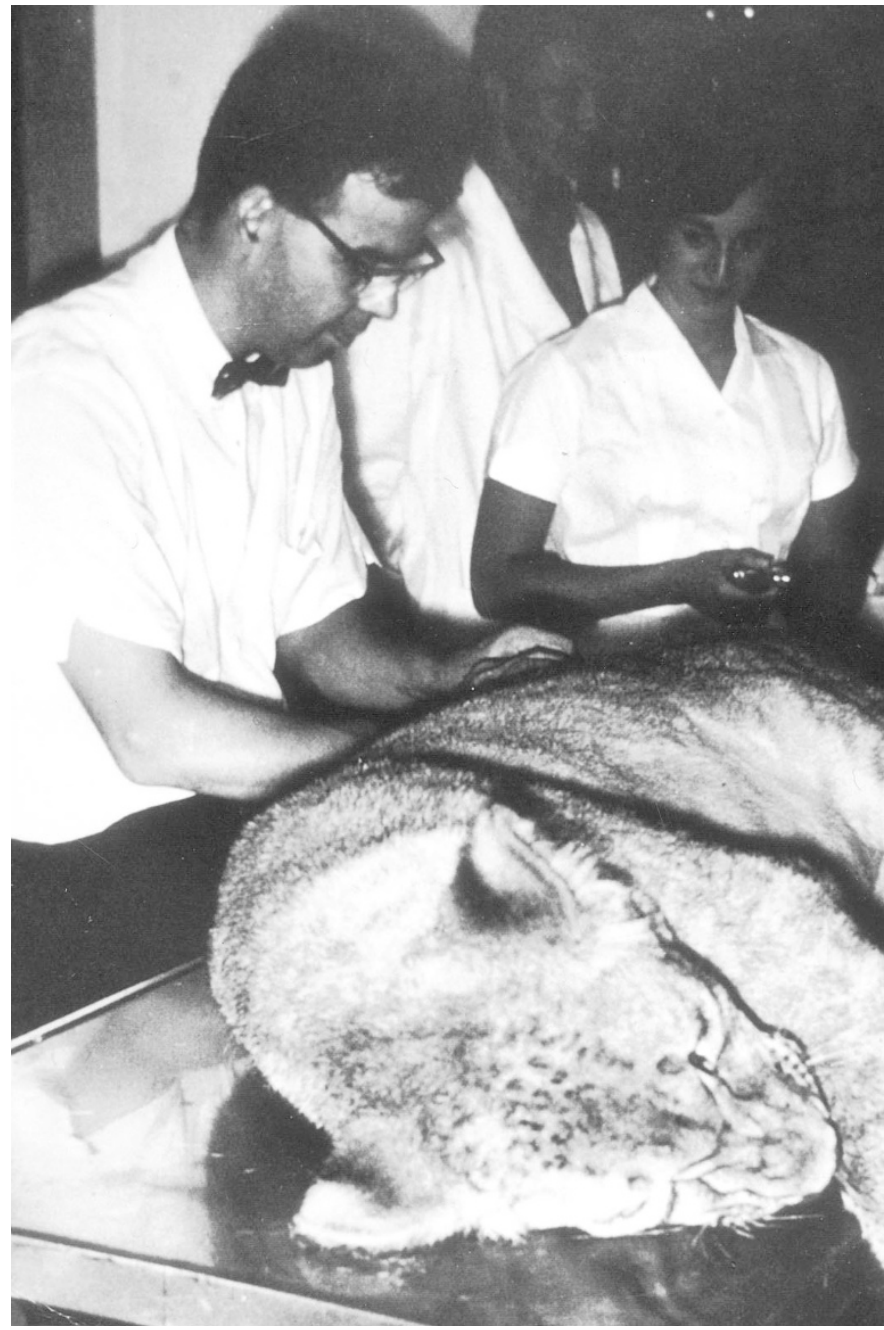

Figure 3. Howard Pearson performing a bone marrow aspiration from a lion, 1965.

program was established in the early 1970s, iron-fortified formulas were provided. In New Haven, Howard was able to show a marked and dramatic decrease in the prevalence of iron deficiency anemia in the high-risk, inner-city population after implementation of the WIC program. This finding was subsequently confirmed by other studies around the nation. Clearly this low-technology advance has prevented illness in a highrisk population and benefited literally millions of children.

In 1990, Howard Pearson was elected vice president and then served as president of the American Academy of Pediatrics. During these very interesting years, Howard had a number of unique opportunities. One of those was to indulge one of his life-long passions, while sitting in the Presidential Library of the Clinton White House. No, Monica wasn't there and he didn't have to testify before a select committee of the Congress, but he did complete his crossword puzzle, a passion which he continues on a daily basis.

In response to a query by an AAP member in 1992, he and Dr. James Strain appointed a special task force on infant sleeping positions and SIDS. This task force worked rapidly and produced the AAP recommendation on sleep positioning in only 3 mo. This recommendation was subsequently accepted 
by the National Institutes of Health and the Centers for Disease Control and led to the national campaign appropriately termed "Back to Sleep." Howard's important role in expediting what ordinarily would have been a long and tortuous process through the AAP committee bureaucracy was fundamental to the implementation of this important project, which has resulted in a significant decrease in the incidence of sudden infant deaths.

In 1986, Paul Newman (Fig. 4; shown on the right, in case you weren't certain) enlisted Howard Pearson (shown on the left) to help create a special camp for children with cancer and serious blood disorders. In less than $18 \mathrm{mo}$, the Hole in the Wall Gang Camp was conceived, planned, designed, constructed, and opened for campers. As Howard is fond of pointing out, if this had been a Yale project, 14 years later we would still be appointing committees, convening task forces, doing feasibility studies, and reviewing executive reports. The multimillion-dollar, architect-designed Hole in the Wall Gang Camp is no ordinary camp. It serves children with very significant degrees of illness. An onsite medical and nursing staff provides a wide spectrum of treatment and support for these children. Howard has served as both the executive director and the medical director of the camp and continues to spend many weeks each summer as "Doc," the name by which the campers and counselors have come to know and love him. The camp serves over 1,000 children each summer and has developed innovative special sessions for children with sickle cell diseases, vertically transmitted HIV/AIDS, and siblings of children with cancer and serious blood diseases. It has led to the development of other camps under the sponsorship of Mr. Newman, both in this country and in Europe. For Howard, most importantly, the camp experience has allowed him to return to one of his favorite pastimes, the creation of totem poles. He has carved nine totem poles, each one larger, more complex, and whimsical than the preceding ones.

In addition to these contributions, Howard has been an amateur (at least by his own account) pediatric historian and has contributed to our understanding of our past, which can only enlighten us in the future. He has given selflessly of his

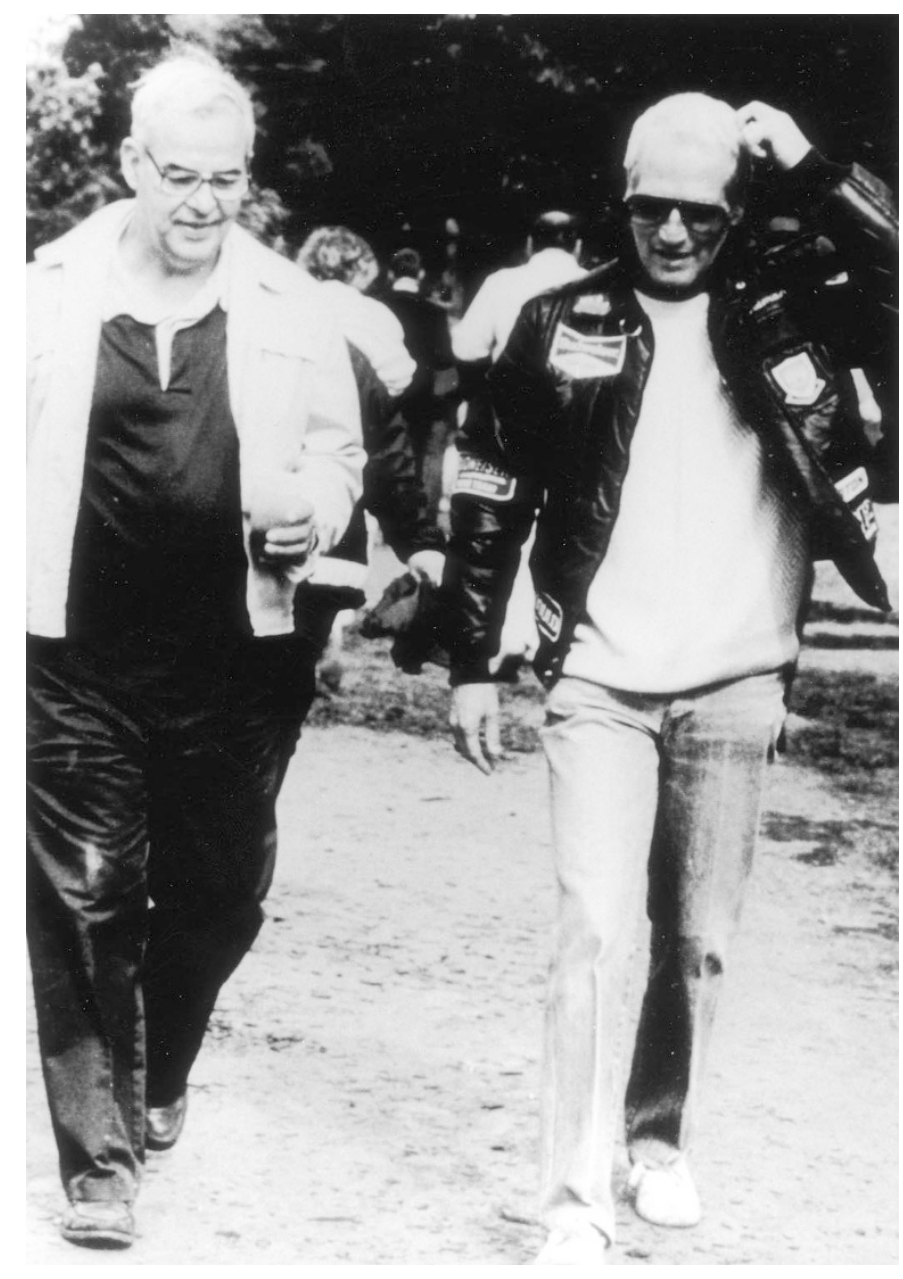

Figure 4. Howard Pearson and Paul Newman at the Hole in the Wall Gang Camp, 1988.

time to national societies and patient groups and has received many recognitions and awards. He has published more than 250 scientific articles and continues to contribute papers to the pediatric literature that advance the understanding of pediatrics and childhood disease. 